\title{
The 21-Gene Recurrence Score Assay for Node- Positive, Early-Stage Breast Cancer and Impact of RxPONDER Trial on Chemotherapy Decision- Making: Have Clinicians Already Decided?
}

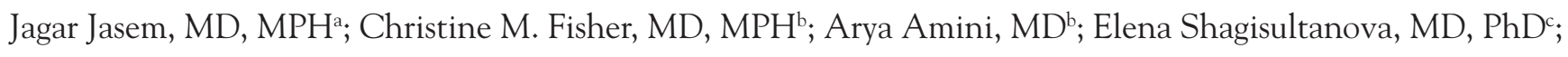
Rachel Rabinovitch, $\mathrm{MD}^{\mathrm{b}}$; Virginia F. Borges, MD, MMScc; Anthony Elias, MDc; and Peter Kabos, MDc

\begin{abstract}
Background: The 21-gene recurrence score (RS) assay is retrospectively validated for assessing prognosis and benefit from chemotherapy in hormone receptor-positive, early-stage breast cancer (EBC) with low RS. We hypothesized that oncologists have already incorporated the RS assay for decision-making in higher-risk, node-positive disease, despite the lack of prospective data and contrary to NCCN Guideline recommendations. This study provides the first analysis of trends and differences in RS use and therapeutic implications in a population-based data set of patients with node-positive EBC. It also assesses the impact of the RxPONDER trial on clinicians' chemotherapy recommendations. Methods: Node-positive EBC cases diagnosed during 2010 through 2012 and included in the National Cancer Data Base were used. Multivariate logistic regression was used to estimate test use and impact on chemotherapy recommendations. Results: The RS assay was ordered for $16.5 \%$ of the 80,405 identified patients. Of all variables, the RS assay had the strongest association with chemotherapy recommendation, with adjusted odds ratios (AORs) of 19 for scores $>30$. Odds of chemotherapy recommendation were significantly lower for the group who received the test (AOR, $0.21 ; 95 \% \mathrm{Cl}, 0.20-0.22$ ). When divided based on the cutoff point of 25 adopted by the RxPONDER trial, those with an RS of 18 to 25 had significantly lower odds of chemotherapy recommendation compared with those with an RS of 26 to 30 (AOR, 0.32; $95 \% \mathrm{Cl}, 0.26-0.40$ ). Test use was lower for blacks, community centers, uninsured/governmentally insured patients, higher tumor grade, larger tumor size, and more nodes involved. Chemotherapy recommendation was higher for patients of younger age, with private insurance, and with higher tumor grade, size, and number of nodes involved. Black patients had significantly higher RS (AOR, 1.37; $95 \%$ $\mathrm{Cl}, 1.25-1.79)$. Conclusions: The RS assay influences clinicians' chemotherapy recommendation in node-positive EBC. Clinicians are using the inclusion criteria of the RXPONDER trial before its final release. Black patients have higher RS, likely representing worse biology. Significant differences exist in test use and clinical implications based on race, insurance, and facility.
\end{abstract}

\section{Background}

Adjuvant chemotherapy was once considered the standard of care for patients with primary breast cancer with tumors $>1 \mathrm{~cm}$ regardless of axillary lymph node involvement. ${ }^{1-3}$ However, given disease recurrence rates of

From the Departments of anternal Medicine, ${ }^{b}$ Radiation Oncology, and Internal Medicine, Division of Medical Oncology, University of Colorado, Aurora, Colorado.

Submitted June 22, 2016; accepted for publication December 2, 2016.

The authors have disclosed that they have no financial interests, arrangements, affiliations, or commercial interests with the manufacturers of any products discussed in this article or their competitors.

The data were deidentified and The American College of Surgeons and the Commission on Cancer have not verified and are not responsible for
$<20 \%$ by 10 years postdiagnosis for patients treated with local and/or hormonal therapy alone, most patients with estrogen receptor (ER)-positive, lymph node-negative disease would not benefit from the addition of chemotherapy to their treatment regimen. ${ }^{4}$

the analytic or statistical methods used or the conclusions drawn from these data by the investigators.

Author contributions: Study hypothesis formulation: Fisher, Amini, Shagisultanova, Rabinovitch, Borges, Elias, Kabos. Literature review: Jasem, Kabos. Data analysis: Jasem. Drafting of manuscript: Jasem, Kabos. Critical review of manuscript: Fisher, Amini, Shagisultanova, Rabinovitch, Borges, Elias.

Correspondence: Jagar Jasem, MD, MPH, University of Colorado, 12631 East 17th Avenue Parkway, Aurora, CO 80045.

E-mail: jagar.jasem@ucdenver.edu 
The recurrence score (RS) test (Oncotype DX; Genomic Health Inc., Redwood City, CA) is a reverse-transcription polymerase chain reaction-based assay of 5 reference genes and 16 cancer-related genes, including those associated with cell proliferation, invasion, and hormone response. ${ }^{5}$ It became commercially available in 2004 and uses a continuous scale (from 0 to 100 ) to predict the 10 -year cancer recurrence risk and benefit of adjuvant chemotherapy in patients with early-stage, ER-positive, lymph node-negative disease. ${ }^{5,6}$ The RS assay results are traditionally categorized into low $(\mathrm{RS}<18)$, intermediate (RS 18-30), and high risk ( RS $\geq 31$ ). The cutoff points were chosen based on the retrospective analysis of NSABP trial B-20.4,6

Although originally recommended and validated for lymph node-negative early-stage breast cancer (EBC), ${ }^{4-9}$ retrospective analysis of multiple studies also demonstrated prognostic utility of the RS assay in patients with lymph node-positive EBC. ${ }^{10,11}$ The first of these studies was based on the SWOG-8814 randomized clinical trial, the results of which were published in 2009 and showed that adjuvant treatment including both chemotherapy and tamoxifen yielded a longer survival benefit over tamoxifen alone in hormone receptor (HR)-positive, nodepositive breast cancer. ${ }^{12}$ The data were subsequently retrospectively analyzed using the RS assay as a discriminator for benefit from chemotherapy by tumor biology, and demonstrated that low RS predicted for absence of benefit, high RS predicted for significant benefit, and the intermediate RS group was underpowered but without significant benefit. ${ }^{13}$ This study provided background support for the January 2011 launching of a prospective RxPONDER trial ( $\mathrm{Rx}$ for Positive Node, Endocrine Responsive Breast Cancer) comparing survival rates with or without chemotherapy in addition to antiendocrine therapy for patients with node-positive breast cancer with lowto-intermediate RS. ${ }^{14}$ It enrolled patients with HRpositive and HER2-negative disease who had 1 to 3 axillary lymph nodes involved. Subjects with RS $\leq 25$ were randomly assigned to either hormone therapy alone or combined hormone and chemotherapy. All patients with scores $>25$ were assigned to receive chemotherapy. Accrual is currently underway and results are not yet available.

Although many smaller studies have shown that the RS assay influences clinicians' recommendation for chemotherapy, ${ }^{15-18}$ the first nationwide study that involved Medicare beneficiaries recently showed no change in the use of chemotherapy after adoption of the RS assay. ${ }^{19}$ The NCCN Clinical Practice Guidelines in Oncology for Breast Cancer contain a footnote suggesting that the RS assay can be considered in select patients with 1 to 3 involved ipsilateral axillary lymph nodes, with ER-positive, HER2negative EBC to guide the addition of combination chemotherapy to standard hormone therapy. ${ }^{20} \mathrm{We}$ hypothesized that, despite the lack of prospective data for node-positive disease, clinical practice has been substantially altered by widespread use of the RS assay.

Using a large sample of patients with node-positive EBC diagnosed between January 2010 and December 2012, the current study aims to provide an analysis of current trends and differences in the use and clinical implications of the RS assay in patients with HR-positive, node-positive disease. It analyzes the impact of RxPONDER trial design on clinicians' recommendations regarding chemotherapy before the final release of its results.

\section{Methods}

\section{Data Source and Study Population}

The National Cancer Data Base (NCDB), a nationwide cancer database sponsored by the Commission on Cancer $(\mathrm{CoC})$ of the American College of Surgeons and the American Cancer Society, was used in the current study. It captures approximately $70 \%$ of all newly diagnosed cancers in the United States, and covers approximately 1,500 CoC-accredited hospitals. ${ }^{21}$

All cases of node-positive breast cancer diagnosed from January 2010 to December 2012 with known RS assay status (ie, those with the test known to be ordered and those with tests known not to be ordered) were first selected. In order to check for the factors associated with ordering the test and the effect that ordering the test had on adjuvant chemotherapy recommendation, those who had the test ordered and had pT1, pT2, pN1 (with 1-3 lymph nodes involved), HR-positive, and HER2-negative disease were later selected and compared with those who did not get the test and had corresponding disease status. 
Jasem et al

The RS assay results were classified into low $(<18)$, intermediate $(18-30)$, and high risk $(\geq 31){ }^{4}$ In order to further evaluate the effect of cutoff point of 25 proposed by the RxPONDER trial on chemotherapy decision, the intermediate scores of 18 to 30 were further classified into categories of 18 to 25 and 26 to 30 . Cancer centers were divided according to the NCI classification into (1) community centers that treat 100 to 500 newly diagnosed cancer cases annually, (2) comprehensive community centers that treat $\geq 500$ newly diagnosed cancer cases annually, (3) academic centers that are similar in size to the first group but also provide postgraduate education in $\geq 4$ program areas, and (4) integrated network cancer programs that are a part of a joint venture, with multiple facilities providing integrated care. ${ }^{22,23}$

Charlson comorbidity score (CCI) was used to account for patient comorbidities in the involved study population. This score is a method of predicting mortality based on the weight each comorbid condition has on the life expectancy of patients. ${ }^{24}$

\section{Statistical Analysis}

Multivariate logistic regression analysis was used to calculate the adjusted odds ratios (AORs), 95\% confidence intervals, and $P$ values for the association of selected covariates (age, race, sex, type of facility, insurance status, year of diagnosis, CCI, tumor grade, tumor size, and number of lymph nodes involved) with the outcome variable of "ordering the test" and the odds of "recommending chemotherapy" for each group.

The Hosmer-Lemeshow test was used to check for goodness-of-fit of the regression models. All analyses were performed using SPSS version 18.0 for Windows/MAC (IBM Corp., Armonk, NY). All tests were 2-sided with a significance level of 0.05 .

\section{Results}

\section{Use of the RS Assay in Node-Positive EBC}

From a total of 80,405 lymph node-positive breast cancer cases with known RS assay status, the RS assay was ordered for $13,288(16.5 \%)$ of cases. Of those who had the test ordered, 10,434 (78.5\%) had pT1, pT2, pN1 (with 1-3 lymph nodes involved), HRpositive, and HER2-negative disease. Table 1 shows the differences between patient groups in whom the test was "ordered" and "not ordered" while having the aforementioned disease characteristics. Significantly higher odds of getting the test were observed in older ages (AOR, 1.52; 95\% CI, 1.36-1.71), women (AOR, 1.65 ; 95\% CI, 1.29-2.12), insured patients, and academic centers. Compared with the community centers, comprehensive community, academic, and integrated cancer network programs were all significantly more likely to order the RS assay. Higher trends of ordering the test were observed in 2012 compared with 2010 (AOR, 1.72; 95\% CI, 1.61-1.83). Lower odds were observed in black patients (AOR, 0.77; 95\% CI, 0.70-0.84) and those with grade II disease (AOR, 0.81; 95\% CI, 0.76-0.86), grade III disease (AOR, 0.47; 95\% CI, 0.43-0.51), pT2 (AOR, 0.66; 95\% CI, 0.63-0.70), and more nodes involved by disease on pathology $(\mathrm{AOR}, 0.54 ; 95 \% \mathrm{CI}, 0.50-0.57$ and AOR, 0.29; 95\% CI, 0.26-0.32, for 2- and 3-node involvement, respectively).

\section{Adjuvant Chemotherapy in Node-Positive EBC}

Table 2 demonstrates the odds of recommending chemotherapy for both the ordered and nonordered RS test groups. The nonordered group served as a control for estimating the pattern of chemotherapy recommendations independent from the test score. For this particular group, the odds of recommending chemotherapy were higher for patients with younger age, private insurance, larger tumor size, higher tumor grade, higher CCI, and $\geq 1$ lymph node involved. Similar patterns of chemotherapy recommendation were observed for the group that received the test, with the exception of lack of differences between race and different insurance plans. The overall rate of chemotherapy was $37.5 \%$ for those who received the test and $75.1 \%$ for those who did not. When adjusted for age, race, insurance status, type of facility, tumor size, number of nodes involved, tumor grade, year of diagnosis, and comorbidities, the odds of chemotherapy were significantly lower for the group who received the test (AOR, 0.21;95\% CI, 0.20-0.22) (data not shown). It is noteworthy that although the study adjusted for many predictors associated with the RS score, this would not provide full adjustment for all expected differences in the RS results.

The RS had the highest adjusted odds of recommending chemotherapy, with an AOR as high as 4.51 (95\% CI, 4.51-5.01) and 19.79 (95\% CI, 15.39-92.94) for intermediate and high scores, respectively. When the data were analyzed based on 
21-Gene RS Assay for Node-Positive EBC

Table 1. AORs of Ordering the Recurrence Score Assay for HR-Positive, HER2-Negative, pT1-2, and pN1 Disease

\begin{tabular}{|c|c|c|c|c|c|c|}
\hline \multirow[b]{2}{*}{ Variables } & \multicolumn{2}{|c|}{ Test Ordered } & \multirow[b]{2}{*}{$\begin{array}{l}\text { Crude OR } \\
(95 \%)\end{array}$} & \multirow[b]{2}{*}{$P$ Value } & \multirow[b]{2}{*}{$\begin{array}{c}\text { AOR } \\
(95 \% \mathrm{Cl})\end{array}$} & \multirow[b]{2}{*}{$P$ Value } \\
\hline & $\begin{array}{c}\text { Yes } \\
(\mathrm{N}=10,434) \\
\mathrm{n}(\%)\end{array}$ & $\begin{array}{c}\text { No } \\
(\mathrm{N}=21,991) \\
\mathrm{n}(\%)\end{array}$ & & & & \\
\hline \multicolumn{7}{|l|}{ Age, y } \\
\hline$<45$ & $928(22.0)$ & $3,294(78.0)$ & 1 & & 1 & \\
\hline $45-64$ & $5,969(33.7)$ & $1,1725(66.3)$ & $1.80(1.66-1.95)$ & $<.001$ & $1.42(1.29-1.58)$ & $<.001$ \\
\hline$\geq 65$ & $3,537(33.7)$ & $6,972(66.3)$ & $1.80(1.65-1.95)$ & $<.001$ & $1.52(1.36-1.71)$ & $<.001$ \\
\hline \multicolumn{7}{|l|}{ Sex } \\
\hline Male & $96(22.4)$ & 332 (77.6) & 1 & & 1 & \\
\hline Female & $10,338(32.3)$ & $21,659(67.7)$ & $1.65(1.31-2.07)$ & .01 & $1.65(1.29-2.12)$ & $<.001$ \\
\hline \multicolumn{7}{|l|}{ Race } \\
\hline White & $9,084(33.1)$ & $18,398(66.9)$ & 1 & & 1 & \\
\hline Black & 856 (25.6) & $2,483(74.4)$ & $0.69(0.64-0.75)$ & $<.001$ & $0.77(0.70-0.84)$ & $<.001$ \\
\hline Other & $401(30.0)$ & $936(70.0)$ & $0.86(0.77-0.97)$ & .02 & $0.92(0.80-1.04)$ & .20 \\
\hline \multicolumn{7}{|l|}{ Year of diagnosis } \\
\hline 2010 & $2,547(25.7)$ & $7,355(74.3)$ & 1 & & 1 & \\
\hline 2011 & $3,642(33.3)$ & $7,306(66.7)$ & $1.44(1.35-1.52)$ & $<.001$ & $1.44(1.35-1.54)$ & $<.001$ \\
\hline 2012 & $4,245(36.7)$ & $7,330(63.3)$ & $1.67(1.57-1.77)$ & $<.001$ & $1.72(1.61-1.83)$ & $<.001$ \\
\hline \multicolumn{7}{|l|}{ Type of facility } \\
\hline Community & $956(28.2)$ & $2,434(71.8)$ & 1 & & 1 & \\
\hline $\begin{array}{l}\text { Comprehensive } \\
\text { community }\end{array}$ & $5,108(32.5)$ & $10,618(67.5)$ & $1.22(1.12-1.32)$ & $<.001$ & $1.23(1.12-1.34)$ & $<.001$ \\
\hline Academic & $3,306(35.6)$ & $5,970(64.4)$ & $1.41(1.29-1.53)$ & $<.001$ & $1.43(1.30-1.57)$ & $<.001$ \\
\hline $\begin{array}{l}\text { Integrated cancer } \\
\text { network programs }\end{array}$ & 733 (32.9) & $1,497(67.1)$ & $1.24(1.11-1.40)$ & $<.001$ & $1.22(1.08-1.39)$ & .001 \\
\hline \multicolumn{7}{|c|}{ Charlson comorbidity score } \\
\hline 0 & $8,791(32.4)$ & $18,364(67.6)$ & 1 & & 1 & \\
\hline$\geq 1$ & $1,643(31.2)$ & $3,627(68.8)$ & $0.94(0.88-1.00)$ & .08 & $0.94(0.88-1.01)$ & .13 \\
\hline \multicolumn{7}{|l|}{ Insurance } \\
\hline None & $174(24.5)$ & $535(75.5)$ & 1 & & 1 & \\
\hline Private & $6,220(32.8)$ & $1,2717(67.2)$ & $1.50(1.26-1.78)$ & $<.001$ & $1.40(1.15-1.70)$ & .001 \\
\hline Governmental & $3,937(31.6)$ & $8,504(68.4)$ & $1.42(1.19-1.69)$ & $<.001$ & $1.23(1.00-1.50)$ & .04 \\
\hline \multicolumn{7}{|l|}{ Grade } \\
\hline I & $2,807(41.4)$ & $3,981(58.6)$ & 1 & & 1 & \\
\hline II & $5,659(33.6)$ & $11,177(66.4)$ & $0.71(0.67-0.76)$ & $<.001$ & $0.81(0.76-0.86)$ & $<.001$ \\
\hline III & $1,556(21.2)$ & $5,784(78.8)$ & $0.38(0.35-0.41)$ & $<.001$ & $0.47(0.43-0.51)$ & $<.001$ \\
\hline \multicolumn{7}{|l|}{ Tumor size } \\
\hline pT1 & $6,749(37.8)$ & $11,125(62.2)$ & 1 & & 1 & \\
\hline pT2 & $3,685(25.3)$ & $10,866(74.7)$ & $0.55(0.53-0.58)$ & $<.001$ & $0.66(0.63-0.70)$ & $<.001$ \\
\hline \multicolumn{7}{|c|}{ Number of nodes involved } \\
\hline 1 & $8,070(38.4)$ & $12,939(61.6)$ & 1 & & 1 & \\
\hline 2 & $1,851(23.8)$ & $5,931(76.2)$ & $0.50(0.47-0.53)$ & $<.001$ & $0.54(0.50-0.57)$ & $<.001$ \\
\hline 3 & $513(14.1)$ & $3,121(85.9)$ & $0.26(0.23-0.29)$ & $<.001$ & $0.29(0.26-0.32)$ & $<.001$ \\
\hline
\end{tabular}

Abbreviations: AOR, adjusted odds ratio; HR, hormone receptor; OR, odds ratio. 
Jasem et al

Table 2. AORs of Recommending Chemotherapy in "RS Assay Ordered" and "RS Assay Not Ordered" Groups

\begin{tabular}{|c|c|c|c|c|}
\hline \multirow[b]{2}{*}{ Variables } & \multicolumn{2}{|c|}{ RS Assay Ordered } & \multicolumn{2}{|c|}{ RS Assay Not Ordered } \\
\hline & $\begin{array}{c}\text { AOR } \\
(95 \% \mathrm{Cl})\end{array}$ & $P$ Value & $\begin{array}{c}\text { AOR } \\
(95 \% \mathrm{Cl})\end{array}$ & $P$ Value \\
\hline \multicolumn{5}{|l|}{$\mathrm{RS}$ assay result } \\
\hline$\leq 18$ & 1 & & & \\
\hline $18-30$ & $4.51(4.07-5.01)$ & $<.001$ & - & - \\
\hline$\geq 31$ & $19.79(15.39-25.45)$ & $<.001$ & - & - \\
\hline \multicolumn{5}{|l|}{ Age, y } \\
\hline$<45$ & 1 & & 1 & \\
\hline $45-64$ & $0.44(0.36-0.54)$ & $<.001$ & $0.50(0.41-0.61)$ & $<.001$ \\
\hline$\geq 65$ & $0.20(0.15-0.25)$ & $<.001$ & $0.07(0.06-0.09)$ & $<.001$ \\
\hline \multicolumn{5}{|l|}{ Sex } \\
\hline Male & 1 & & 1 & \\
\hline Female & $1.12(0.65-1.94)$ & .67 & $1.01(0.76-1.32)$ & .93 \\
\hline \multicolumn{5}{|l|}{ Race } \\
\hline White & 1 & & 1 & .05 \\
\hline Black & $0.91(0.77-1.10)$ & .39 & $0.89(0.79-1.00)$ & .39 \\
\hline Other & $1.16(0.90-1.49)$ & .86 & $1.09(0.89-1.22)$ & .05 \\
\hline \multicolumn{5}{|l|}{ Year of diagnosis } \\
\hline 2010 & 1 & & 1 & \\
\hline 2011 & $1.03(0.90-1.17)$ & .63 & $0.92(0.84-1.00)$ & .06 \\
\hline 2012 & $1.00(0.88-1.14)$ & .89 & $0.97(0.88-1.06)$ & .51 \\
\hline \multicolumn{5}{|l|}{ Type of facility } \\
\hline Community & 1 & & 1 & \\
\hline Comprehensive community & $0.92(0.77-1.10)$ & .39 & $0.97(0.87-1.10)$ & .72 \\
\hline Academic & $1.01(0.84-1.22)$ & .86 & $0.98(0.86-1.11)$ & .77 \\
\hline $\begin{array}{l}\text { Integrated cancer network } \\
\text { programs }\end{array}$ & $0.84(0.65-1.08)$ & .18 & $0.98(0.82-1.16)$ & .85 \\
\hline \multicolumn{5}{|l|}{ Insurance } \\
\hline None & 1 & & 1 & \\
\hline Private & $1.20(0.82-1.77)$ & .33 & $1.60(1.23-2.06)$ & $<.001$ \\
\hline Governmental & $0.90(0.60-1.34)$ & .62 & $0.94(0.72-1.22)$ & .65 \\
\hline \multicolumn{5}{|l|}{ Charlson comorbidity score } \\
\hline$\underline{0}$ & 1 & & 1 & \\
\hline$\geq 1$ & $0.84(0.73-0.96)$ & .01 & $0.77(0.70-0.85)$ & $<.001$ \\
\hline \multicolumn{5}{|l|}{ Tumor size } \\
\hline$\underline{\mathrm{pT} 1}$ & 1 & & 1 & \\
\hline рT2 & $1.26(1.14-1.40)$ & $<.001$ & $1.26(1.17-1.36)$ & $<.001$ \\
\hline \multicolumn{5}{|l|}{ Grade } \\
\hline 1 & 1 & & 1 & \\
\hline$\underline{\text { II }}$ & $1.28(1.14-1.44)$ & $<.001$ & $1.66(1.51-1.82)$ & $<.001$ \\
\hline III & $1.93(1.64-2.28)$ & $<.001$ & $2.66(2.38-2.98)$ & $<.001$ \\
\hline \multicolumn{5}{|l|}{ Number of nodes involved } \\
\hline 1 & 1 & & & \\
\hline 2 & $1.61(1.41-1.82)$ & $<.001$ & $1.75(1.60-1.91)$ & $<.001$ \\
\hline 3 & $2.29(1.83-2.87)$ & $<.001$ & $2.20(1.95-2.48)$ & $<.001$ \\
\hline
\end{tabular}

RXPONDER trial

RS $\leq 25:$ OR, 1.

RS > 25: OR, $9.13(95 \% \mathrm{Cl}, 7.72-10.80) ; P<.001$.

Modified

RS <18: OR, 1.

RS 18-25: OR, $3.70(95 \% \mathrm{Cl}, 3.31-4.15) ; P<.001$

RS 26-30: OR, $10.81(95 \% \mathrm{Cl}, 8.68-13.47) ; P<.001$

RS $\geq 31$ : OR, $19.79(95 \% \mathrm{Cl}, 15.39-25.45) ; P<.001$.

Abbreviations: AOR, adjusted odds ratio; OR, odds ratio; RS, recurrence score. 
the categorization proposed by the RxPONDER trial, the AOR of chemotherapy for those with an RS $>25$ was 9.13 (95\% CI, 7.72-10.80). Further categorization of the intermediate group into 18 to 25 and 26 to 30 revealed AORs of 3.70 (95\% CI, 3.31-4.15) and 10.81 (95\% CI, 8.68-13.47), respectively. Of 2,281 patients with an RS of 18 to $25,1,169$ (51.2\%) were recommended chemotherapy versus 423 (74.2\%) of the 570 patients with an RS of 26 to 30 .

Compared with an RS of 26 to 30, a score of 18 to 25 was independently associated with significantly lower odds of chemotherapy recommendation (AOR, 3.01; 95\% CI, 2.43-3.74) (Table 3). Figures 1 and 2 show that chemotherapy was not recommended for almost half of the patients with an RS of 18 to 25 , regardless of tumor size and number of nodes.

\section{Factors Associated With High RS in Node-Positive EBC}

An RS of $\geq 31$ was independently noted for men (AOR, 0.39; 95\% Cl, 0.21-0.74), blacks (AOR, 1.37; 95\% CI, 1.15-1.79), grade II-III tumors (AOR, 26.86; 95\% CI, 18.34-39.33 for grade III), larger tumor size (AOR, 1.65; 95\% CI, 1.31-1.85), and younger ages (AOR, 0.66; 95\% CI, 0.50-0.88 for age $\geq 65$ years; Table 4 ).

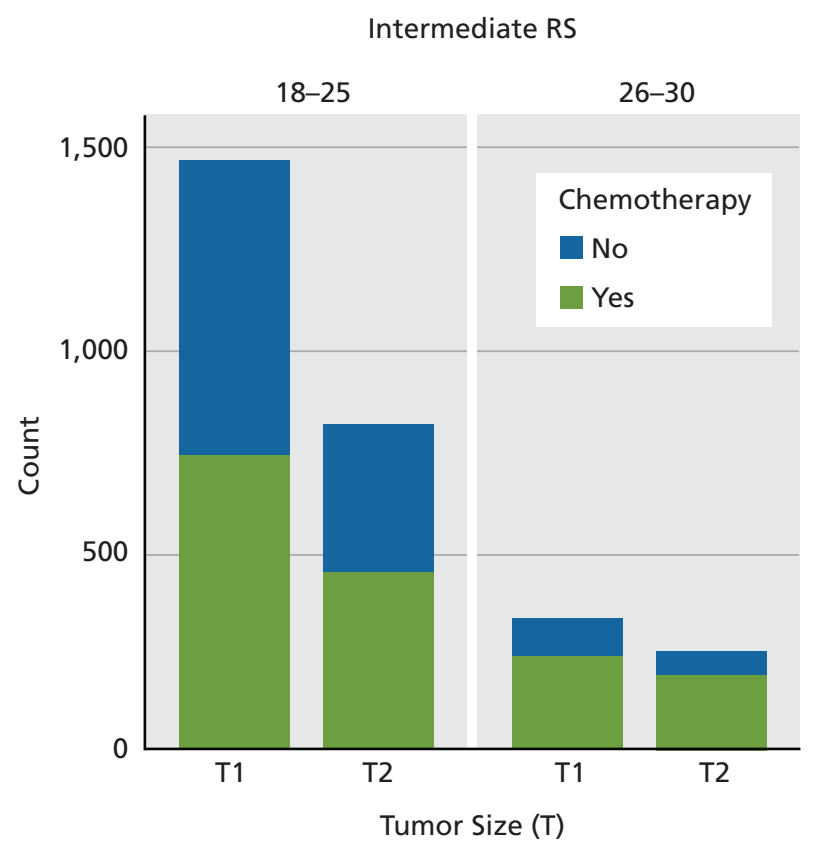

Figure 1. Patterns of chemotherapy for patients with intermediate recurrence scores (RS) based on tumor size.

\section{Discussion}

To our knowledge, this is the first study that analyzes patterns of use, therapeutic implications, and disparity profile of the RS assay for node-positive EBC with 1 to 3 lymph nodes involved using a national cancer database. It is also the first study that analyzes the adoption pattern by medical oncologists and practical impact of the RxPONDER trial in the United States before the final dissemination of trial results.

Our study revealed that the RS assay is an independent predictor of chemotherapy recommendation in node-positive EBC. AORs for the intermediate (18-30) and high (>30) scores were 4 and 19, respectively. The adoption of the test is associated with a trend for decrease in chemotherapy recommendations by clinicians. However, when the intermediate group was divided based on the RxPONDER cutoff level of 25 , those with scores of 18 to 25 had significantly lower odds of receiving a chemotherapy recommendation compared with those with scores of 26 to 30 (AOR, 0.3). The observed difference in chemotherapy recommendations between both intermediate groups was independent from factors such as age, race, comorbidities, insurance status, type of facility, tumor size, and number of nodes involved. In a similar but smaller study of 111 patients with ER-positive $\mathrm{EBC}$, the rate of chemotherapy administration

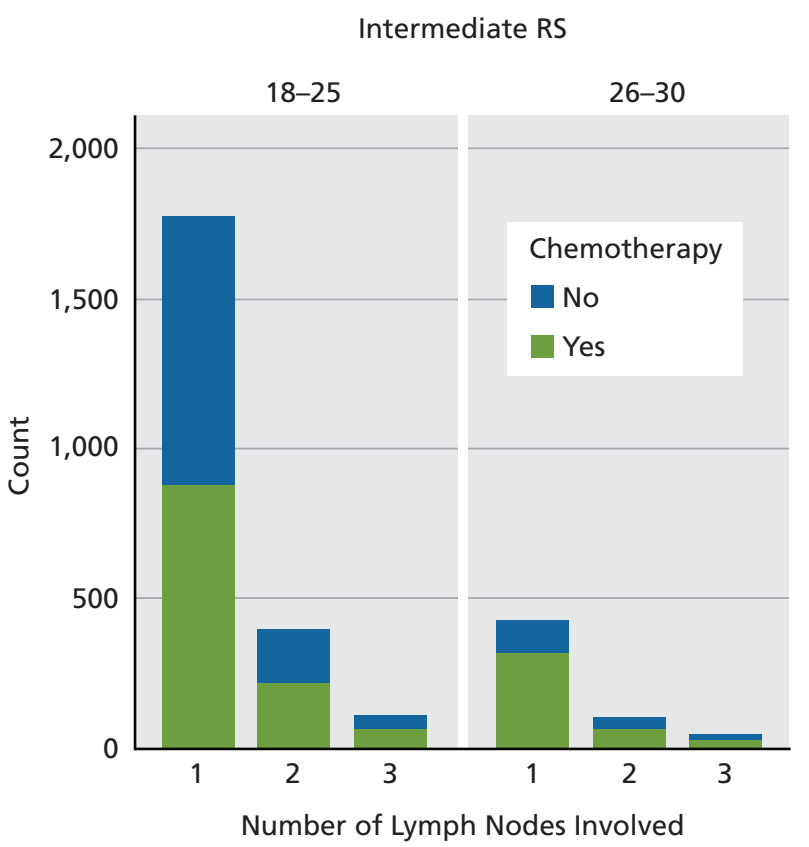

Figure 2. Patterns of chemotherapy for patients with intermediate recurrence scores (RS) based on number of nodes involved. 
Jasem et al

decreased by $58 \%$ for an RS of 18 to 25 and increased by $64 \%$ for an RS of 26 to 30 after using the RS test, with the RS being the only significant predictor of treatment changes in multivariate analysis. ${ }^{25}$ Our study and the one by Fried and Moskovitz $z^{25}$ likely indicate that the inclusion criteria of the RxPONDER trial are already being adopted by oncologists before the intended prospective validation of the RS assay in this disease setting has been completed. This adoption of use is occurring despite strong recommendations to continue routine administration of adjuvant chemotherapy to patients with node-positive breast cancer regardless of tumor biology. ${ }^{26}$

It is noteworthy that the adoption of new treatment modalities while prospective studies were ongoing has previously occurred in the oncology field, at a potential detriment to patients. For many years, use of high-dose chemotherapy intensification followed by autologous bone marrow or stem cell rescue was used and adopted as a standard of care before the completion of prospective randomized trials that were ultimately negative. ${ }^{27,28}$ Similarly, in 2003, the FDA approved the use of gefitinib for treating nonsmall cell lung cancer through an accelerated process based on a single uncontrolled study of 216 patients and despite $>200$ reports of the potentially fatal side effects of the agent. Nevertheless, more $>200,000$ patients used gefitinib in the following year. A controlled clinical trial was finally conducted and failed to demonstrate therapeutic benefit. ${ }^{29}$

As expected, in our study, higher odds of recommending chemotherapy were observed with larger tumor size, higher tumor grade, and more nodes involved. Moreover, tumor grade had the highest association with higher RS. This reflects the advantage of using the multigene RS assay in predicting tumor biology. ${ }^{30,31}$ Lower trends of ordering RS for higher tumor grades, larger tumor size, and higher number of nodes involved is most likely due to higher trends of recommending chemotherapy for such disease characteristics regardless of the RS result.

Racial differences in incidence, management, and prognosis of breast cancer have been reported in numerous prior studies. ${ }^{9,32-36}$ Black women have higher mortality rates from breast cancer compared with women of other races. ${ }^{33,37}$ Studies have also shown that black women are more likely to have triple-negative tumors, reflecting less favorable tumor biology. However, survival disparities seem to

\begin{tabular}{|c|c|c|c|c|}
\hline \multirow[b]{2}{*}{ Variables } & \multicolumn{2}{|c|}{ Chemotherapy } & \multirow[b]{2}{*}{$\begin{array}{c}\text { AOR } \\
(95 \% \mathrm{Cl})\end{array}$} & \multirow[b]{2}{*}{$P$ Value } \\
\hline & $\begin{array}{c}\text { Yes } \\
\text { n (\%) }\end{array}$ & $\begin{array}{c}\text { No } \\
\text { n (\%) }\end{array}$ & & \\
\hline \multicolumn{5}{|l|}{ Intermediate RS } \\
\hline $18-25$ & $1,169(51.2)$ & $1,112(48.8)$ & 1 & \\
\hline $26-30$ & $423(74.2)$ & $147(25.8)$ & $3.08(2.47-3.85)$ & $<.001$ \\
\hline \multicolumn{5}{|l|}{ Age, y } \\
\hline$<45$ & 231 (78.6) & $63(21.4)$ & 1 & \\
\hline $45-64$ & $1,019(61.2)$ & $645(38.8)$ & $0.51(0.36-0.73)$ & $<.001$ \\
\hline$\geq 65$ & $342(38.3)$ & $551(61.7)$ & $0.21(0.14-0.31)$ & $<.001$ \\
\hline \multicolumn{5}{|l|}{ Race } \\
\hline White & $1,369(55.2)$ & $1,113(44.8)$ & 1 & \\
\hline Black & 133 (56.6) & $102(43.4)$ & $0.89(0.66-0.21)$ & .47 \\
\hline Other & $77(70.0)$ & $33(30.0)$ & $1.55(0.98-2.45)$ & .06 \\
\hline \multicolumn{5}{|l|}{ Tumor size } \\
\hline pT1 & $967(54.0)$ & $825(46.0)$ & 1 & \\
\hline pT2 & $625(59.0)$ & $434(41.0)$ & $1.17(0.98-1.39)$ & .06 \\
\hline \multicolumn{5}{|c|}{ Number of nodes involved } \\
\hline 1 & $1,196(54.4)$ & $1,003(45.6)$ & 1 & \\
\hline 2 & $294(58.8)$ & $206(41.2)$ & $1.24(1.10-1.55)$ & .04 \\
\hline 3 & $102(67.1)$ & $50(32.9)$ & $1.72(1.17-2.54)$ & .006 \\
\hline \multicolumn{5}{|l|}{ Insurance } \\
\hline Private & $1,091(62.7)$ & $650(37.3)$ & 1 & \\
\hline Governmental & $450(44.0)$ & $573(56.0)$ & $0.80(0.64-1.00)$ & .05 \\
\hline \multicolumn{5}{|l|}{ Type of facility } \\
\hline Community & $140(57.6)$ & $103(42.4)$ & 1 & \\
\hline $\begin{array}{l}\text { Comprehensive } \\
\text { community }\end{array}$ & $754(53.6)$ & $644(46.4)$ & $0.73(0.59-1.10)$ & .06 \\
\hline Academic & $524(57.1)$ & $394(42.9)$ & $0.82(0.60-1.12)$ & .22 \\
\hline \multicolumn{5}{|c|}{ Charlson comorbidity score } \\
\hline 0 & $1,372(57.2)$ & $1,028(42.8)$ & 1 & \\
\hline$\geq 1$ & $220(48.8)$ & $231(51.2)$ & $0.84(0.67-1.04)$ & .11 \\
\hline
\end{tabular}

Abbreviations: AOR, adjusted odds ratio; RS, recurrence score.

persist for HR-positive patients when adjusted for various demographic characteristics, tumor stages, and treatment strategies adopted for managing breast cancer. ${ }^{35,36}$ Our study revealed that black patients are more likely to have higher RS results even when accounting for factors such as age, grade, tumor size, and number of lymph nodes involved. This finding is compatible with a previous study by Lund et $\mathrm{al}^{38}$ that revealed a 2 -fold increased likelihood of black women to have high RS test results compared with white women based on a retrospective analysis of cancer data from 3 Atlanta hospitals from 2005 


\begin{tabular}{|c|c|c|c|c|}
\hline \multirow[b]{2}{*}{ Variable } & \multicolumn{2}{|c|}{ RS Assay } & \multirow[b]{2}{*}{$\begin{array}{c}\text { AOR } \\
(95 \% \mathrm{Cl})\end{array}$} & \multirow[b]{2}{*}{$P$ Value } \\
\hline & $\begin{array}{c}\text { Low/ } \\
\text { Intermediate } \\
\text { N (\%) }\end{array}$ & $\begin{array}{l}\text { High } \\
\text { N (\%) }\end{array}$ & & \\
\hline \multicolumn{5}{|l|}{ Sex } \\
\hline Male & $75(82.4)$ & $16(17.6)$ & 1 & \\
\hline Female & $9,214(93.3)$ & $658(6.7)$ & $0.39(0.21-0.74)$ & .004 \\
\hline \multicolumn{5}{|l|}{ Age, $y$} \\
\hline$<45$ & 787 (89.6) & $91(10.4)$ & 1 & \\
\hline $45-64$ & $5,345(93.7)$ & $358(6.3)$ & $0.65(0.50-0.85)$ & .002 \\
\hline$\geq 65$ & $3,158(93.3)$ & $225(6.7)$ & $0.66(0.50-0.88)$ & .005 \\
\hline \multicolumn{5}{|l|}{ Race } \\
\hline White & $8,120(93.6)$ & $559(6.4)$ & 1 & \\
\hline Black & 729 (89.9) & $82(10.1)$ & $1.37(1.25-1.79)$ & .02 \\
\hline Other & $356(93.4)$ & $25(6.6)$ & $0.94(0.60-1.47)$ & .80 \\
\hline \multicolumn{5}{|l|}{ Grade } \\
\hline I & $2,652(98.9)$ & $30(1.1)$ & 1 & \\
\hline II & $5,166(95.4)$ & $251(4.6)$ & $3.95(2.69-5.80)$ & $<.001$ \\
\hline III & $1,100(74.6)$ & $374(25.4)$ & $26.86(18.34-39.33)$ & $<.001$ \\
\hline \multicolumn{5}{|c|}{ Tumor size } \\
\hline pT1 & $6,136(95.1)$ & $317(4.9)$ & 1 & \\
\hline $\mathrm{pT2}$ & $3,153(89.8)$ & $357(10.2)$ & $1.65(1.31-1.85)$ & $<.001$ \\
\hline \multicolumn{5}{|c|}{ Number of nodes involved } \\
\hline 1 & $7,202(93.3)$ & $519(6.7)$ & 1 & \\
\hline 2 & 1,449 (93.3) & $119(6.7)$ & $0.82(0.65-1.02)$ & .08 \\
\hline 3 & $438(92.4)$ & $36(7.6)$ & $0.74(0.50-1.09)$ & .13 \\
\hline
\end{tabular}

Abbreviations: AOR, adjusted odds ratio; RS, recurrence score.

through 2009. It is also compatible with another nationwide study that revealed a trend for high RS among black women with node-negative EBC. ${ }^{9}$ Although our study did not reveal racial differences in recommending chemotherapy, black patients were significantly less likely to receive RS testing compared with women of other races. This finding is again compatible with observations by Lund et al. ${ }^{38}$

Insurance status parallels the socioeconomic status of the population and is an indicator of healthcare accessibility, affordability, and use. ${ }^{39}$ Privately insured patients were more likely to be recommended chemotherapy if they were not tested; such a difference disappeared for those who were tested. Insured patients were more likely to have the RS test compared with uninsured patients, and the privately insured more than the governmentally insured.
Most studies that involved trends in use of the RS assay involved either academic ${ }^{40}$ or community facilities. ${ }^{41-43}$ A recent meta-analysis of 23 studies revealed that $74 \%$ were conducted in academic centers, and the remainder in either community hospitals or mixed community and academic centers, but none compared RS assay trends across facilities. ${ }^{21}$ Compared with patients treated at community centers, those treated at more comprehensive and academic centers were more likely to get tested with the RS assay. However, no differences between the centers were noted in terms of recommending chemotherapy in the group that had the test ordered and the group that did not.

Male breast cancer represents approximately 1\% of all breast cancer cases. ${ }^{44,45}$ Previous studies showed similar RS results for men and women. However, these studies included both node-positive and nodenegative cases. ${ }^{45,46}$ Our study revealed higher trends of getting the RS test among women. When used as a categorical variable, more men than women fell into the high-risk group. However, the mean RS value was similar for both sexes when used as a continuous variable. In general, sex differences in our study should be interpreted with caution given the small number of men included. Additional studies that have more male cases are needed to evaluate true sex differences.

Our study has certain limitations. Information about the RS test may be erroneously or underreported given the relatively recent adoption of the test. Patients who did not have the test may be deemed inappropriate for testing and/or receiving chemotherapy for reasons not otherwise documented in the $\mathrm{NCDB}$, and hence unaccounted for in our analysis. Although the NCDB covers approximately twothirds of all newly diagnosed cancers, its coverage is found to be lower for elderly patients and those of Hispanic and Alaskan Natives/American Indian origins. ${ }^{21}$ The study does not involve patients who were tested from 2013 onward, representing a lag in NCDB data availability. The trends of getting the test and recommending chemotherapy may be different in the more recent years given the presumed wider availability, accessibility, and adoption rates of the RS. The study does not provide information about other pathologic features that may potentially affect clinicians' decision on ordering RS, such as extracapsular extension of disease. The lower representation of uninsured patients may limit the generaliz- 
ability of the study. Although the date of RS ordering is not reported in the database, the temporal relation between RS ordering and chemotherapy recommendation can be reasonably established given the fact that RS is used as a clinical tool for making chemotherapy recommendations.

\section{Conclusions}

Our study revealed that the use of the RS assay influenced clinicians' decision regarding adjuvant chemotherapy recommendations in patients with node- positive EBC with 1 to 3 lymph nodes involved. Significant differences exist in use of the assay and chemotherapy recommendations based on race, insurance status, and type of facility. Despite lack of prospective data, the oncologists who order the RS assay appear to be already recommending chemotherapy based more on tumor biology represented by the RS results than tumor staging or standard pathologic assessments. Furthermore, it appears that they tend to recommend against using chemotherapy in patients with node-positive $\mathrm{EBC}$ with $\mathrm{RS}<25$, influenced by the RxPONDER trial design.

\section{References}

1. Chen $C$, Dhanda R, Tseng WY, et al. Evaluating use characteristics for the oncotype $\mathrm{dx} 21$-gene recurrence score and concordance with chemotherapy use in early-stage breast cancer. J Oncol Pract 2013;9:182-187.

2. Eifel P, Axelson JA, Costa J, et al. National Institutes of Health Consensus Development Conference Statement: adjuvant therapy for breast cancer, November 1-3, 2000. J Natl Cancer Inst 2001;93:979-989.

3. Goldhirsch A, Wood WC, Gelber RD, et al. Meeting highlights: updated international expert consensus on the primary therapy of early breast cancer. J Clin Oncol 2003;21:3357-3365.

4. Paik S, Shak S, Tang G, et al. A multigene assay to predict recurrence of tamoxifen-treated, node-negative breast cancer. $N$ Engl J Med 2004;351:2817-2826.

5. Paik S. Development and clinical utility of a 21-gene recurrence score prognostic assay in patients with early breast cancer treated with tamoxifen. Oncologist 2007;12:631-635.

6. Sparano JA, Paik S. Development of the 21-gene assay and its application in clinical practice and clinical trials. J Clin Oncol 2008;26:721-728.

7. Habel LA, Shak S, Jacobs MK, et al. A population-based study of tumor gene expression and risk of breast cancer death among lymph nodenegative patients. Breast Cancer Res 2006;8:R25.

8. Sparano JA, Gray RJ, Makower DF, et al. Prospective validation of a 21gene expression assay in breast cancer. N Engl J Med 2015;373:2005-2014.

9. Jasem J, Amini A, Rabinovitch R, et al. 21-gene recurrence score assay as a predictor of adjuvant chemotherapy administration for early-stage breast cancer: an analysis of use, therapeutic implications, and disparity profile. J Clin Oncol 2016;34:1995-2002.

10. Albain KS, Barlow WE, Shak S, et al. Prognostic and predictive value of the 21-gene recurrence score assay in postmenopausal women with nodepositive, oestrogen-receptor-positive breast cancer on chemotherapy: a retrospective analysis of a randomised trial. Lancet Oncol 2010;11:55-65.

11. Dowsett M, Cuzick J, Wale C, et al. Prediction of risk of distant recurrence using the 21-gene recurrence score in node-negative and node-positive postmenopausal patients with breast cancer treated with anastrozole or tamoxifen: a TransATAC study. J Clin Oncol 2010;28:1829-1834.

12. Albain KS, Barlow WE, Ravdin PM, et al. Adjuvant chemotherapy and timing of tamoxifen in postmenopausal patients with endocrineresponsive, node-positive breast cancer: a phase 3, open-label, randomised controlled trial. Lancet 2009;374:2055-2063.

13. Paik S, Tang G, Shak S, et al. Gene expression and benefit of chemotherapy in women with node-negative, estrogen receptor-positive breast cancer. J Clin Oncol 2006;24:3726-3734.

14. SWOG RxPONDER Trial (S1007): Patient Information. Available at: http://swog.org/Visitors/S1007/patients.asp. Accessed February 20, 2017.

15. Yamauchi $H$, Nakagawa $C$, Takei $H$, et al. Prospective study of the effect of the 21-gene assay on adjuvant clinical decision-making in Japanese women with estrogen receptor-positive, node-negative, and node-positive breast cancer. Clin Breast Cancer 2014;14:191-197.

16. de Boer RH, Baker C, Speakman D, et al. The impact of a genomic assay (Oncotype DX) on adjuvant treatment recommendations in early breast cancer. Med J Aust 2013;199:205-208.
17. Eiermann W, Rezai M, Kummel S, et al. The 21-gene recurrence score assay impacts adjuvant therapy recommendations for ER-positive, nodenegative and node-positive early breast cancer resulting in a risk-adapted change in chemotherapy use. Ann Oncol 2013;24:618-624.

18. Geffen DB, Abu-Ghanem S, Sion-Vardy N, et al. The impact of the 21-gene recurrence score assay on decision making about adjuvant chemotherapy in early-stage estrogen-receptor-positive breast cancer in an oncology practice with a unified treatment policy. Ann Oncol 2011;22:2381-2386.

19. Dinan MA, Mi X, Reed SD, et al. Association between use of the 21 gene recurrence score assay and receipt of chemotherapy among Medicare beneficiaries with early-stage breast cancer, 2005-2009. JAMA Oncol 2015;1:1098-1109.

20. Gradishar WJ, Anderson BO, Balassanian R, et al. NCCN Clinical Practice Guidelines in Oncology: Breast Cancer. Version 2.2016. Accessed February 20, 2017. To view the most recent version of these guidelines, visit NCCN.org.

21. Lerro CC, Robbins AS, Phillips JL, Stewart AK. Comparison of cases captured in the national cancer data base with those in population-based central cancer registries. Ann Surg Oncol 2013;20:1759-1765.

22. Information for CoC-Accredited programs. American College of Surgeons Web site. Available at: https://www.facs.org/quality-programs/cancer/coc/ apply/categories\#. Accessed February 20, 2017.

23. NCI Dictionary of Cancer Terms. National Cancer Institute Web site. Available at: https://www.cancer.gov/publications/dictionaries/cancerterms. Accessed February 20, 2017

24. Charlson ME, Pompei P, Ales KL, MacKenzie CR. A new method of classifying prognostic comorbidity in longitudinal studies: development and validation. J Chronic Dis 1987;40:373-383.

25. Fried G, Moskovitz M. Treatment decisions in estrogen receptor-positive early breast cancer patients with intermediate oncotype DX recurrence score results. Springerplus 2014;3:71.

26. Hayes DF. Targeting adjuvant chemotherapy: a good idea that needs to be proven! J Clin Oncol 2012;30:1264-1267.

27. Borges VF, Elias AD. The era of high-dose chemotherapy for breast cancer: revisiting a troubled quest. J Clin Oncol 2011;29:3205-3206.

28. Welch HG, Mogielnicki J. Presumed benefit: lessons from the American experience with marrow transplantation for breast cancer. BMJ 2002;324:1088-1092.

29. Woloshin S, Schwartz LM. What's the rush? The dissemination and adoption of preliminary research results. J Natl Cancer Inst 2006;98:372373.

30. Venook AP, Niedzwiecki D, Lopatin M, et al. Biologic determinants of tumor recurrence in stage II colon cancer: validation study of the 12-gene recurrence score in Cancer and Leukemia Group B (CALGB) 9581. J Clin Oncol 2013;31:1775-1781.

31. Eroles P, Bosch A, Perez-Fidalgo JA, Lluch A. Molecular biology in breast cancer: intrinsic subtypes and signaling pathways. Cancer Treat Rev 2012;38:698-707.

32. Roberts MC, Weinberger M, Dusetzina SB, et al. Racial variation in adjuvant chemotherapy initiation among breast cancer patients receiving oncotype DX testing. Breast Cancer Res Treat 2015;153:191-200. 
21-Gene RS Assay for Node-Positive EBC

33. Aizer AA, Wilhite TJ, Chen $\mathrm{MH}$, et al. Lack of reduction in racial disparities in cancer-specific mortality over a 20-year period. Cancer 2014;120:1532-1539

34. Bickell NA, Wang JJ, Oluwole S, et al. Missed opportunities: racial disparities in adjuvant breast cancer treatment. J Clin Oncol 2006;24:13571362.

35. Hershman DL, Unger JM, Barlow WE, et al. Treatment quality and outcomes of African American versus white breast cancer patients retrospective analysis of Southwest Oncology studies S8814/S8897. J Clin Oncol 2009;27:2157-2162.

36. Menashe I, Anderson WF, Jatoi I, Rosenberg PS. Underlying causes of the black-white racial disparity in breast cancer mortality: a population-based analysis. J Natl Cancer Inst 2009;101:993-1000.

37. Weir HK, Thun MJ, Hankey BF, et al. Annual report to the nation on the status of cancer, 1975-2000, featuring the uses of surveillance data for cancer prevention and control. J Natl Cancer Inst 2003;95:1276-1299.

38. Lund MJ, Mosunjac M, Davis KM, et al. 21-Gene recurrence scores: racial differences in testing, scores, treatment, and outcome. Cancer 2012;118:788-796.

39. Adler NE, Newman K. Socioeconomic disparities in health: pathways and policies. Health Aff (Millwood) 2002;21:60-76.

40. Asad J, Jacobson AF, Estabrook A, et al. Does oncotype DX recurrence score affect the management of patients with early-stage breast cancer? Am J Surg 2008;196:527-529.
41. Holt S, Bertelli G, Brinkworth E, et al. Results from a prospective clinical study on the impact of Oncotype DX on adjuvant treatment decision making in a cohort of 142 UK patients [abstract]. Presented at the 34th Annual CTRC-AACR San Antonio Breast Cancer Symposium; December 6-10, 2011; San Antonio, Texas. Abstract P5-14-26.

42. Effect of menopausal status and oncotype recurrence score on treatment choice for early-stage receptor-positive breast cancer [abstract]. Presented at the 2009 Breast Cancer Symposium; October 8-10, 2009; San Francisco, California. Abstract 356

43. Oratz R, Paul D, Cohn AL, Sedlacek SM. Impact of a commercial reference laboratory test recurrence score on decision making in early-stage breast cancer. J Oncol Pract 2007;3:182-186.

44. Fentiman IS, Fourquet A, Hortobagyi GN. Male breast cancer. Lancet 2006;367:595-604.

45. Grenader T, Yerushalmi R, Tokar M, et al. The 21-gene recurrence score assay (Oncotype DX) in estrogen receptor-positive male breast cancer: experience in an Israeli cohort. Oncology 2014;87:1-6.

46. Shak S, Palmer G, Baehner FL, et al. Molecular characterization of male breast cancer by standardized quantitative RT-PCR analysis: first large genomic study of 347 male breast cancers compared to 82,434 female breast cancers [abstract]. J Clin Oncol 2009;27(Suppl):Abstract 549.

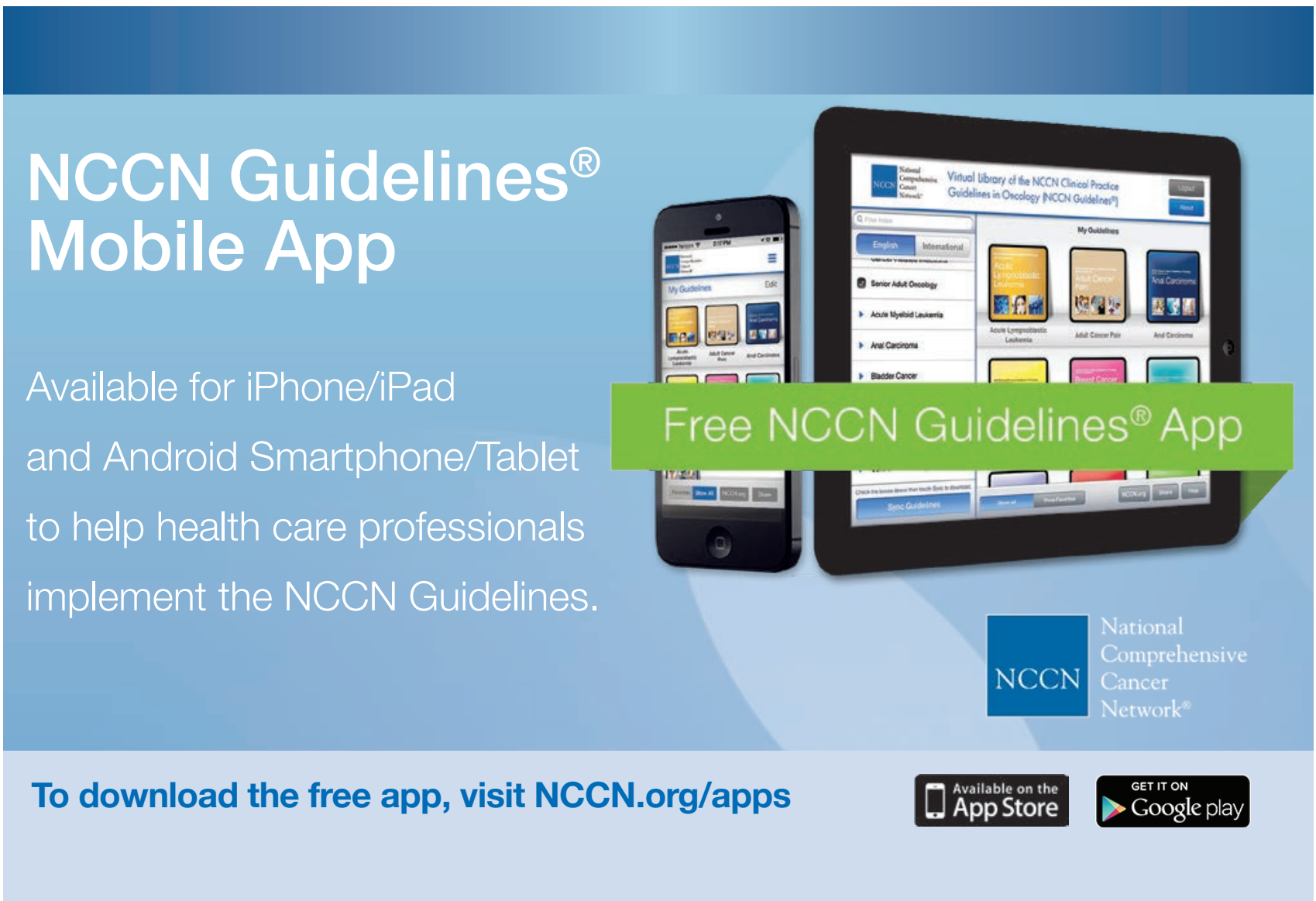

